SAT0510

CUTANEOUS MANIFESTATIONS IN IDIOPATHIC INFLAMATORY MYOPATHIES: FACTORS ASSOCIATED WITH CALCINOSIS

T. Cobo-lbáñez ${ }^{1}$, F.J. López-Longo ${ }^{2}$, B. Joven ${ }^{3}$, S. Muñoz-Fernández ${ }^{1}$, P. Carreira ${ }^{3}$, M. Á. Blázquez ${ }^{4}$, I. Llorente ${ }^{5}$, J.C. López Robledillo ${ }^{6}$, R. Almodóvar ${ }^{7}$ P. García-De la Peña ${ }^{8}$, M.C. Barbadillo ${ }^{9}$, A. Pérez ${ }^{10}$, L. Lojo ${ }^{11}$, M.J. García de Yébenes ${ }^{12}$, L. Nuño ${ }^{13}$ on behalf of REMICAM. ${ }^{1}$ Rheumatology, H. Infanta Sofía, Universidad Europea; ${ }^{2}$ Rheumatology, H. Gregorio Marañón; ${ }^{3}$ Rheumatology, $H$. Doce de Octubre; ${ }^{4}$ Rheumatology, H. Ramón y Cajal; ${ }^{5}$ Rheumatology, H. La Princesa; ${ }^{6}$ Rheumatology, H. Niño Jesús; ${ }^{7}$ Rheumatology, H. Fundación Alcorcón; ${ }^{8}$ Rheumatology, H. HM Sanchinarro; ${ }^{9}$ Rheumatology, H. Puerta de Hierro;

${ }^{10}$ Rheumatology, H. Príncipe de Asturias; ${ }^{11}$ Rheumatology, H. Infanta Leonor,

${ }^{12}$ Rheumatology, Instituto de Salud Musculoesquelética; ${ }^{13}$ Rheumatology, H. La Paz, Madrid, Spain

Background: Calcinosis is a cutaneous manifestation that produces disability and complications in patients with idiopathic inflammatory myopathies (IIM). Studies about associated factors are limited.

Objectives: To investigate cutaneous manifestations and factors associated with calcinosis in patients with IIM from the REMICAM registry.

Methods: A multicenter retrospective study (1980-2014) was performed. Patients were classified as primary dermatomyositis (DM), primary polymyositis (PM), cancer associated myositis (CAM), overlap myositis (OM), inclusion body myositis, immune-mediated necrotising myopathy (IMNM) and juvenile myositis (JuM). A description of the cutaneous manifestations in each subgroup of IIM was done. The associations between calcinosis and demographic data, clinical characteristics, antibodies and treatments were analysed independently for JuM and adult IIM.

Results: 479 patients were included, of whom $49(10 \%)$ had calcinosis with the following distribution: $27 \mathrm{JuM}(55 \%), 9 \mathrm{DM}(18 \%), 9 \mathrm{OM}(18 \%), 3 \mathrm{PM}(6 \%)$ and 1 IMNM (2\%). Non- characteristic cutaneous manifestations were more prevalent in $\mathrm{DM}, \mathrm{OM}, \mathrm{CAM}$ and IMNM. At multivariate analysis, disease duration $(\mathrm{OR}=2$; $\mathrm{p}=0.016)$, immunoglobulin treatment $(\mathrm{OR}=5.68 ; \mathrm{p}=0.036)$ and immunosuppressants $(\mathrm{OR}=8.94 ; \mathrm{p}=0.01)$ were associated with calcinosis in JuM. In addition, dysphagia (OR=21.3; $\mathrm{p}=0.008$ ), positivity for anti-PM-Scl ( $\mathrm{OR}=34.1 ; \mathrm{p}=0.01$ ), baseline ESR $(\mathrm{OR}=1.05 ; \mathrm{p}=0.04)$ and interstitial lung disease $(\mathrm{OR}=10.2$; $\mathrm{p}=0.039$ ) were associated with calcinosis in adult.

Conclusions: Our results suggest that factors associated with calcinosis might be different in adult and juvenile myositis, but in both cases, they are related to more severe disease.

Disclosure of Interest: None declared

DOI: 10.1136/annrheumdis-2018-eular.2629

\section{SAT0511 PRACTICAL SUGGESTIONS ON INTRAVENOUS ILOPROST IN RAYNAUD'S PHENOMENON AND DIGITAL ULCER SECONDARY TO SYSTEMIC SCLEROSIS: SYSTEMATIC LITERATURE REVIEW AND EXPERT CONSENSUS}

T. Schioppo ${ }^{1}$, F. Ingegnoli ${ }^{1}, 2$, Y. Allanore ${ }^{3}$, R. Caporali ${ }^{4}$, M. Colaci $^{5}$, O. Distler 6 , D. E. Furst ${ }^{7,8,9}$, N. Hunzelmann ${ }^{10}$, F. lannone ${ }^{11}$, D. Khanna ${ }^{12}$, M. Matucci-Cerinic ${ }^{13,14}$ ${ }^{1}$ Rheumatology, ASST Pini-CTO; ${ }^{2}$ Dept Clinical Sciences and Community Health, Univ Milan, Milan, Italy; ${ }^{3}$ Cochin Hospital, Rheumatology A dept, Univ Paris Descartes, Paris, France; ${ }^{4}$ Div Rheumatology, Univ Pavia, IRCCS S. Matteo Foundation, Pavia; ${ }^{5}$ Rheumatology, Univ Modena and Reggio Emilia, Modena, Italy; ${ }^{6}$ Dept Rheumatology, Univ Hospital Zurich, Zurich, Switzerland; ${ }^{7}$ UCLA, Los Angeles; ${ }^{8}$ Univ Washington, Seattle, USA; ${ }^{9}$ Univ Florence, Florence, Italy; ${ }^{10}$ Dept Dermatology, Univ Cologne, Cologne, Germany, ${ }^{11}$ DETO-Section of

Rheumatology, Bari, Italy; ${ }^{12}$ Univ Michigan, Ann Arbor, USA; ${ }^{13}$ Dept Experimental and Clinical Medicine, Univ Florence; ${ }^{14}$ Div Rheumatology, AOUC Careggi,

Florence, Italy

Background: Raynaud's phenomenon (RP) and digital ulcer (DU) are prominent features of SSc. According to the 2017 EULAR recommendations, intravenous (IV) iloprost (ILO) may be used for RP and DU after failure of oral therapies. Where available, IV ILO is indicated in RP secondary to systemic sclerosis (SSc) for 3-5 days with no other advice about the regimen (dosage, duration and frequency). Objectives: To provide a systematic review focused on IV ILO use in SSc RP and DU and to perform a meta-analysis. In the case of lack of data, a Delphi consensus was performed to provide practical suggestions about ILO usage in SSc $\mathrm{RP}$ and DU and to propose a research agenda for future studies.

Methods: The systematic review of the literature on IV ILO in SSc patients complicated by DU and RP was performed according to PRISMA guidelines and the meta-analysis to the GRADE system. A three-step web-based Delphi consensus was designed if not enough data were available from the literature.

Results: The review flow process is outlined in figure 1. The meta-analysis could not be performed due to insufficient literature data about dosage, regimen and frequency of IV ILO. Therefore, a three-round Delphi exercise was performed to identify and establish a consensus about IV ILO use in SSc RP and DU. Expert consensus was reached at the third step for the following items:

- Severe or refractory to oral therapy RP, IV ILO 0.5 and $2.0 \mathrm{ng} / \mathrm{kg} / \mathrm{min}, 1-3$ days monthly.

- DU healing, IV ILO 0.5 and $2.0 \mathrm{ng} / \mathrm{kg} / \mathrm{min}$ up to the maximum tolerated dose the first day of therapy, $1-3$ days monthly.

DU prevention, IV ILO 0.5 and $2.0 \mathrm{ng} / \mathrm{kg} / \mathrm{min}, 1$ day monthly.

- Research agenda: trials for head-to-head comparison and for regimen assessment.

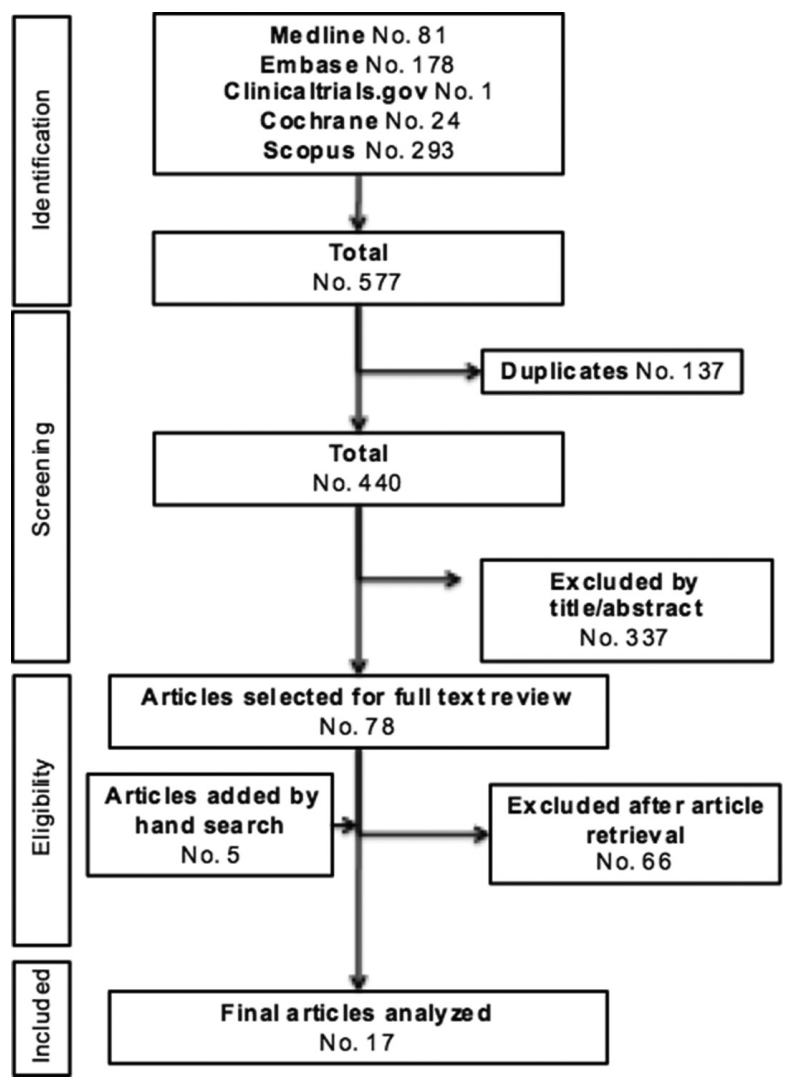

Conclusions: IV ILO is currently available in some countries with the approved indication only for RP-SSc for 3-5 days. Our data, based on expert consensus, suggest a 1-3 days monthly regimen for RP and DU healing and 1 day monthly for DU prevention. These suggestions may allow clinicians to decide how to personalise the IV ILO therapy according to patients' needs. Although these suggestions are intended for clinical setting use, it will be necessary to formally validate the present suggestions in future clinical trials.

Acknowledgements: The consensus meeting has been supported by Italfarmaco.

Disclosure of Interest: None declared

DOI: 10.1136/annrheumdis-2018-eular.3271

\section{SAT0512 SAFETY AND EFFICACY OF LENABASUM IN REFRACTORY SKIN-PREDOMINANT DERMATOMYOSITIS SUBJECTS TREATED IN AN OPEN LABEL EXTENSION OF TRIAL JBT101-DM-001}

V.P. Werth ${ }^{1,2}$, B. Patel ${ }^{1,2}$, J.S. Concha ${ }^{1,2}$, J. Okawa $^{1,2}$, D. Pearson ${ }^{1,2}$, E. Hejazi $^{1,2}$, R. Feng ${ }^{1,2}$, C. Cornwall ${ }^{3}$, N. Dgetluck ${ }^{3}$, S. Constantine $^{3}$, A. Aggarwal $^{3}$, B. White ${ }^{3}$. ${ }^{1}$ Philadelphia Veteran Affairs Medical Center, ${ }^{2}$ University of Pennsylvania, Philadelphia; ${ }^{3}$ Corbus Pharmaceuticals, Inc., Norwood, USA

Background: Lenabasum (aka anabasum, JBT-101) is a selective cannabinoid receptor type 2 agonist that activates resolution of innate immune responses. It is a synthetic, oral, non-immunosuppressive small molecule. Lenabasum showed acceptable safety and tolerability and evidence of clinical benefit in 22 subjects with refractory, skin-predominant dermatomyositis (DM) in Phase 2 trial JBT101DM-001 (NCT02466243).

Objectives: This study evaluated safety and efficacy of open-label dosing of lenabasum in moderately-to-severely active skin-predominant DM in subjects who were refractory to or intolerant of hydroxychloroquine treatment. 